\title{
Condensation heat transfer in square, triangular, and semi- circular mini-channels
}

Melanie Derby ${ }^{\text {a }}$, Hee Joon Lee ${ }^{\text {a,b }}$, Yoav Peles ${ }^{\text {a }}$, Michael K. Jesen ${ }^{\text {a,* }}$

${ }^{a}$ Department of Mechanical, Aerospace, and Nuclear Engineering

Rensselaer Polytechnic Institute

Troy, NY 12180, United States

${ }^{\mathrm{b}}$ Department of Mechanical Engineering

Kookmin University

Seoul, 136-702, South Korea

${ }^{*}$ Corresponding author

Address: JEC $20492^{\text {nd }} \mathrm{Fl}$

Rensselaer Polytechnic Institute

$1108^{\text {th }} \mathrm{St}$

Troy, NY 12180

Telephone: 15182762843

Fax: 15182766025

Contact E-mail: jensem@rpi.edu 


\begin{abstract}
Condensation heat transfer coefficients in mini-channels were measured with smaller measurement uncertainties than previously obtained using three specially designed copper test sections. Single-phase experiments validated the approach. Data are reported for R134a in $1 \mathrm{~mm}$ square, triangular, and semi-circular multiple parallel minichannels cooled on three sides. A parametric study was conducted over a range of conditions for mass flux, average quality, saturation pressure, and heat flux. Mass flux and quality were determined to have significant effects on the condensation process, even at lower mass fluxes, while saturation pressure, heat flux, and channel shape had no significant effects. The lack of shape effects were attributed to the three-sided cooling boundary conditions. Because there was no significant surface tension enhancement, the macro-scale Shah (2009) correlation best predicted the data, with a mean average error (MAE) of 20 to 30\% for all geometries.
\end{abstract}

\title{
Keywords
}

Condensation, Heat Transfer, Minichannel, Channel Shape, Correlation

\section{Introduction}

Lightweight and compact condensers for vapor compression cycles have a variety of applications from electronics’ cooling to transportation. However, as reported in the literature, uncertainties in measured condensation heat transfer coefficients can be as high as $\pm 20 \%$ to \pm $40 \%$ due to the challenges of measuring condensation heat fluxes and wall temperatures at the micro- and mini-scales. Large uncertainties encourage condenser over-design. Typical 
approaches to measure condensation heat transfer coefficients in the micro- and mini-scale utilize fluid-to-fluid heat exchangers, which can have high experimental uncertainties at the low heat duties encountered in micro- and mini-scale condensation.

Several approaches to measure condensation heat transfer coefficients at the macro-scale have been later applied to the mini- and micro-scale. Akers [1] and Dobson and Chato [2] used fluid-to-fluid heat exchangers, where one fluid was condensing and the other was the coolant. The heat transfer rate was obtained through a coolant-side energy balance. To obtain condensation heat transfer coefficients, thermocouples or thermistors attached to the tube wall measured temperature. This approach was also utilized by Cavallini et al. [3] in a multiple channel, $1.4 \mathrm{~mm}$ diameter condenser. An energy balance on the fluid-to-fluid heat exchanger measured heat duty while sensors in two obstructed channels measured wall temperatures. Large cooling water temperature difference was necessary for the temperature measurement's uncertainty to be small compared to the measured temperature difference, which may not have been achieved.

Condensation heat transfer rates can also be found by conducting an energy balance before and after the test section on a pre- and post-heater. Wang et al. [4] constructed an air-cooled condensation test section, with $2 \mathrm{~kW}$ pre- and post-heaters, used in conjunction with an aircooled test section to determine heat transfer rates. Similarly, Agarwal and Garimella [5] determined test section heat transfer rates utilizing $80 \mathrm{~W}$ pre- and post-heaters with parallel channels on the order of $100 \mu \mathrm{m}$ hydraulic diameter in a copper wafer. Several challenges were encountered in their design (e.g., large quality changes, pressure drops, and significant axial conduction), which required a complex numerical conjugate heat transfer analysis to determine condensation heat transfer coefficients. 
Another common macro-scale condensation heat transfer coefficient measurement approach applied to mini- and micro-scale condensation is the Wilson plot method, reviewed by Fernandez-Seara et al. [6]. The Wilson plot is a graphical method that determines heat transfer coefficients without direct measurement of wall temperatures. The Wilson plot and modified Wilson plot have several limitations at the mini- and micro-scale. A functional form of the coolant heat transfer coefficient must be assumed, and the condensation heat transfer resistance must be the dominant resistance. Garimella and Bandhauer [7] determined in an uncertainty analysis that a 1.6 condensation-to-coolant resistance ratio (better suited to the macro-scale than the mini- or micro-scale) was needed to obtain the heat transfer coefficient within $\pm 15 \%$. However, the modified Wilson plot has been used by some researchers, such as Webb and Ermis [8], to determine condensation heat transfer coefficients at the mini-scale in parallel channels of diameter 0.44 to $1.56 \mathrm{~mm}$.

Garimella and Bandhauer [7] and Bandhauer et al. [9] further adapted the Wilson plot method for the mini-scale by creating a "thermal amplification" loop. The test section consisted of a counter-flow fluid-to-fluid heat exchanger; however, there were competing objectives in the design of the test section, as the desire for low quality changes and, thus, heat duties, conflicted with the need for the condensing resistance to dominate in the Wilson plot method. The "thermal amplification” loop separated the cooling portion into two loops: one high mass flow rate, low thermal resistance loop for the Wilson plot method, and a second lower mass flow rate and larger temperature change loop for heat duty measurement.

Matkovic et al. [10] measured the coolant water and wall temperature profiles along a fluidto-fluid heat exchanger. The wall temperature measurements were fit in a polynomial form, and the local derivative of the coolant temperature profile was used to determine condensation heat 
flux while studying condensation of R134a in a $0.96 \mathrm{~mm}$ channel. However, this approach was extremely sensitive to temperature measurements.

Shin and Kim [11,12] determined condensation heat transfer rates by comparing an aircooled test section to an electrically heated test section. Refrigerant flowed through one tube, while an identical copper tube with fins contained a $D C$ resistive heater; heat transfer rate was assumed to be the same in both tubes when comparable surface temperatures were obtained by varying the $D C$ power. Although this method was able to measure heat transfer in single channels, two practical barriers to implementing this method existed: measuring extremely low mass flow rates and constructing two identical finned copper test sections.

Baird et al. [13] used thermoelectric coolers to determine condensation heat flux. R11 and HFC123 in single tubes of diameter $0.92 \mathrm{~mm}$ and $1.95 \mathrm{~mm}$ were cooled by ten thermoelectric coolers, or TECs, were used to create ten "quasi-local” energy balances. For a TEC, the cold side cooling rate was obtained through an equation with material properties provided by the manufacturer. "Quasi-local” heat transfer coefficients were found in this novel approach. However, recent work by Derby et al. [14] utilized TECs as heat flux sensors for single-phase and condensation of R134a, and showed several shortcomings of TECs as heat flux sensors. Despite rigorously calibrating the TECs in a special calibration apparatus, experimental uncertainties in single phase Nusselt number of more than $100 \%$ were found due to inconsistencies in the devices themselves. Also, hot-side and cold-side thermal resistance were a possible explanation of for the unpredictable performance of the cooling output of the TECs. In conclusion, TECs are useful for cooling applications, but need further consideration before implementing as condensation heat flux sensors.

Measuring condensing heat fluxes and wall temperatures presents a challenge, as there is no direct electrical means to measure the heat flux, as in boiling. Additionally, the small heat duties 
encountered at the micro- and mini-scale pose a problem for macro-scale fluid-to-fluid heat exchanger techniques, as the measured heat fluxes are very sensitive to temperature measurements. The thermal amplification loop, developed by Garimella and Bandhauer [7] and Bandhauer [9], was a rigorous approach to measuring condensation heat transfer coefficients, yet uncertainties were $\pm 21 \%$, on average, with uncertainties as high as $\pm 40 \%$. Clearly, new condensation heat flux and wall temperature need to be developed.

Although measurement of mini- and micro-scale condensation heat fluxes and wall temperatures (and, thus, heat transfer coefficients) has been difficult, researchers have identified several important parameters. Of prime importance is the increase of condensation heat transfer coefficients with decreasing channel diameter, which makes mini- and micro-scale condensation attractive. Shin and Kim [12] tested three circular and three rectangular channels, with hydraulic diameters ranging from $0.493 \mathrm{~mm}$ to around $1 \mathrm{~mm}$, and found condensation heat transfer coefficient to be proportional to the hydraulic diameter, $D_{h}^{-0.54}$ for circular channels and $D_{h}^{-0.45}$ for rectangular channels. However, Baird et al. [13] found little effect of diameter between a $0.92 \mathrm{~mm}$ and $1.95 \mathrm{~mm}$ tube. In the micro-channel diameter range, Agarwal and Garimella [5] studied channels with hydraulic diameters of around 100 to $160 \mu \mathrm{m}$, and reported heat transfer coefficients of $20-70 \mathrm{~kW} / \mathrm{m}^{2} \mathrm{~K}$ - higher than seen in other literature using larger channels.

In addition to channel diameter, several studies investigated the dependency of the condensation heat transfer coefficient on the channel shape, which modified surface tension forces. Shin and Kim [12] found the length-averaged condensation heat transfer coefficients to be higher in rectangular channels at lower mass fluxes, and higher in circular channels at higher mass fluxes. Wang and Rose [15] argued that in non-circular channels condensate gathered at the corners, thins the liquid film and lower thermal resistance compared to the uniform film of a 
circular channel. Eventually, however, the corners in a non-circular channel floods, hindering the benefit gained from the thin liquid film. Therefore, depending on channel length and other variables, length-averaged heat transfer coefficients in a circular tube could be higher or lower than a rectangular channel. Agarwal et al. [16] studied six non-circular channels (i.e., barrelshaped, $N$-shaped, $W$-shaped, rectangular, square, and triangular) with hydraulic diameters ranging from 0.424 to $0.839 \mathrm{~mm}$. Because of the differing hydraulic diameters, the best performing shape was not identified, but shape with sharper corners ( $N$-shaped, $W$-shaped, and triangular) were modeled best with a mist flow model. The remaining shapes were described best using an annular flow model.

In virtually all studies, mass flux and quality exerted the largest effects on condensation heat transfer coefficients. Exceptions to this trend, found by Shin and Kim [12] and Matkovic [10], were encountered only at lower mass flux of 100 to $200 \mathrm{~kg} / \mathrm{m}^{2} \mathrm{~s}$, where experimental errors were higher. Further experimentation is needed to draw conclusions about the dependency of condensation heat transfer coefficients at low mass fluxes.

Other variables influencing condensation heat transfer included heat flux and system pressure. Few researchers have observed a dependence of heat transfer coefficient on condensation heat flux, possibly because the fluid-to-fluid heat exchanger test sections did not allow for variation of heat flux. Baird et al. [13] reported a "significant” impact of condensation heat flux on heat transfer coefficients, especially at higher qualities, and also noted higher heat transfer coefficients, in general, at lower system pressures. However, Agarwal and Garimella [5] varied saturation temperature of $\mathrm{R} 134 \mathrm{a}$ between $30^{\circ} \mathrm{C}$ and $60^{\circ} \mathrm{C}$, but did find any significant dependence on pressure. 


\section{Experimental Method and Apparatus}

To overcome the large uncertainties associated with measuring condensation heat flux and wall temperatures for condensing flows, an experimental test section was designed and constructed to produce heat transfer coefficient data with smaller uncertainties than previously obtained. The test section design, inspired by pool boiling experiments, utilized a copper block as a heat flux and wall temperature sensor. For condensation experiments, the test section was installed in a pump loop designed for R134a operating at temperatures up to $50^{\circ} \mathrm{C}$.

\subsection{Test section design}

Since previous mini- and micro-scale condensation heat transfer experiments had large heat transfer rate and wall temperature uncertainties, boiling heat transfer literature was examined to see an advanced measurement method for heat transfer rate that could be applied to condensation. One such method was a heat flux sensor developed by Kedzierski and Worthington [17] and used by Kedzierski [18]. In Kedzierski’s experiments, pool boiling occurred on an enhanced copper surface, which was fabricated on one side of a copper block that was used as a heat flux sensor. Embedded thermocouples in the copper block measured the temperature gradient and, thus, through Fourier's law, the heat flux and wall temperature. This approach was investigated and adopted for the present flow condensation experiments.

The basic test section design employed multiple parallel channels to increase heat duty, thus

temperature gradients in Figure 1. Square, triangular, and semi-circular 1-mm hydraulic diameter channels were machined into three test sections instead of attaching a separate channel in Figure 2, to eliminate thermal interface resistance between the channels and copper block to reduce uncertainties. A Buna-N O-ring sealed the test section to a Delrin ${ }^{\circledR}$ cover plate. Fluid impinged 
on the header areas through a $4.7 \mathrm{~mm}$ hole in the Delrin ${ }^{\circledR}$, passed through the channels and outlet header, and exited out through a $4.7 \mathrm{~mm}$ hole in the Delrin ${ }^{\circledR}$. The test section was cooled by a water-filled serpentine heat exchanger; coolant water temperatures were controlled using a thermal bath. As the total coolant temperature change did not exceed $1{ }^{\circ} \mathrm{C}$, the boundary condition was approximately constant temperature.

Condensing heat fluxes were measured in the three segments using five thermocouples (located 14, 19, 24, 29, and $34 \mathrm{~mm}$ from the bottom of the square channel, and comparable for the other geometries) and a near-wall thermocouple (3 $\mathrm{mm}$ from the channel bottom) to extrapolate wall temperature in each measuring segment. Oxygen-free copper was selected because of its well documented, high thermal conductivity of $391 \mathrm{~W} / \mathrm{m} \mathrm{K}$.

FLUENT $^{\circledR}$ simulations were used to validate the one-dimensional conduction assumption and wall temperature extrapolation. The temperature gradient in the block was determined to be linear 10 to $15 \mathrm{~mm}$ from the channels, as there were some nonlinearities near the wall. Temperature profiles from FLUENT ${ }^{\circledR}$ were input into the data reduction program, written in EES. At low Reynolds numbers $(R e=930)$, representative of single-phase flows, the mean average error in heat flux from FLUENT $^{\circledR}$ and the data reduction program was $8.3 \%$, while at higher Reynolds numbers $(R e=63,000)$, with heat transfer coefficients comparable to condensation, the mean average error in heat flux was 3.2\%. Agreement between FLUENT ${ }^{\circledR}$ and data reduction fluid and wall temperatures ranged from 3 to $10 \%$ for the wall-fluid temperature difference. Therefore, the one dimensional conduction assumption and determination of wall and fluid temperatures were validated.

Next, the heat transfer in the headers was investigated. Since the header area participated in the heat transfer process, the total header areas were designed to be small, consisting of less than $7 \%$ of the total heat transfer area, and the overall test section is $T$-shaped, so the headers are not 
being directly cooled. Furthermore, FLUENT ${ }^{\circledR}$ laminar simulations of a Reynolds number of 930 and turbulent $k-\varepsilon$ simulations of various Reynolds numbers (3200, 6475, 32000, 63000) showed that the inlet header heat transfer coefficient, necessary for energy balances to determine fluid temperature (single-phase) and quality (two-phase), was twice that of the second measuring measuring segment, while the exit header heat transfer coefficient was equivalent to that of the second measuring measuring segment.

To decrease axial conduction between measuring segments, especially important in single phase experiments where the fluid temperature changes by $10 \mathrm{~K}$, the segments were separated by 1.59 mm slots (Figure 1). FLUENT ${ }^{\circledR}$ simulations showed for a single phase mass flux of 571 $\mathrm{kg} / \mathrm{m}^{2} \mathrm{~s}$, axial temperature variation in a measuring segment (at a position $17 \mathrm{~mm}$ from the channels) varied by less than $0.15 \mathrm{~K}$ when there were axial slots. Without the axial slots, the axial temperature variation doubled. Therefore, axial slots between measuring segments reduced axial conduction, thus improving measurement accuracy of condensation heat fluxes. Further details on test section modeling and design can be found in Derby [19].

\subsection{Apparatus}

A closed loop (Figure 3) was designed so test sections with different channel geometries could be interchanged and tested over a wide range of operating conditions. The external gear pump allowed for a range of mass fluxes, while the pump bypass loop provided even finer mass flow rate control. A bank of four parallel rotameters measured this wide range of mass flow rates with a maximum volumetric flow rate of $250 \mathrm{ml} / \mathrm{min}$. To suppress two-phase flow instabilities a throttle valve was installed upstream of the electric pre-heater, which set the test section inlet condition (subcooled liquid to superheated vapor). Because of the importance of the pre-heater energy balance on evaluating fluid temperatures (for single-phase) and quality (for two-phase), a 
guard heater was wrapped around the pre-heater to minimize heat losses, and experiments provided estimates of heat losses. Test section inlet and outlet temperature probes were used for validation purposes of single-phase energy balances, and, in addition to pressure measurements, provided a check on saturation temperatures for two-phase experiments. A differential pressure transducer measured the pressure drop across the test section, while an absolute pressure transducer measured pressure at the test section outlet. When the test section exit quality was above zero, a fin-and-tube post-condenser fully condensed the mixture. System pressure was adjusted using a bladder accumulator.

\subsection{Experimental Procedures}

Single-phase validation and condensation experiments were conducted. For single phase experiments, subcooled liquid entered the test section and low single-phase heat transfer coefficients produced small temperature gradients. Therefore, by heating the refrigerant and cooling the water bath, large temperature changes $(<10 \mathrm{~K})$ were achieved across the test section, resulting in measureable temperatures gradients. For condensation experiments, the saturation temperature was set using the bladder accumulator. In order to minimize heat losses in the preheater for both single-phase and condensation experiments, guard heater temperatures were matched to within $1{ }^{\circ} \mathrm{C}$ of a thermocouple attached to the pre-heater wall, and this temperature was used in an experimental heat loss model. For both single-phase and condensation tests,

initial experiments recorded temperatures and pressures for over an hour. Subsequently, steady state was defined when copper block temperatures, loop temperatures, and pressures were constant for at least five minutes. After steady state occurred, temperature and voltage measurements were recorded by LabVIEW ${ }^{\circledR}$ for 30 seconds and averaged and later reduced.

\subsection{Data Reduction}


For single-phase and condensation experiments, the goal was to determine heat transfer coefficients were obtained by the following expression:

$$
h_{i}=\frac{q_{i}^{\prime \prime}}{\left(T_{w, i}-T_{f, i}\right)}
$$

where $h_{i}$ was the segment-averaged heat transfer coefficient, $q_{i}^{\prime \prime}$ was the channel heat flux, $T_{w, i}$ was the segment-averaged wall temperature, $T_{f, i}$ was the segment-averaged fluid temperature, and $i$ was the index representing measuring segments 1 , 2, and 3. In order to obtain the channel heat flux, the temperature gradient was determined through a curve fit (five thermocouples and excluding the near-wall thermocouple) as:

$$
T_{i}=C_{0, i}+C_{1, i} Y_{i}
$$

where $T_{i}$ was temperature, $C_{0, i}$ was the $y$-axis intercept, $C_{1, i}$ was the slope of the line (and temperature gradient), and $Y$ was the thermocouple's distance from the bottom of the channel. A sample experimental temperature gradient is shown in Figure 4. The heat transfer rate in each measuring segment, $\dot{Q}_{i}$, was then calculated assuming one-dimensional conduction,

$$
\dot{Q}_{i}=-k W L_{s e g, i} \frac{d T}{d y}
$$

where $k$ was the thermal conductivity of oxygen-free copper, $W$ was the width of the block, $L_{\text {seg, } I}$ was the length of the measuring segment, and $d T / d y_{i}$ was the temperature gradient. The segment heat flux was simply the heat transfer rate divided by the channel surface area; this experimental set-up used three-sided cooling.

Additionally, wall and fluid temperatures were needed to calculate heat transfer coefficients. Wall temperature was then obtained through a polynomial curve fit of the temperatures from the six thermocouples: 


$$
T_{i}=A_{0, i}+A_{1, i} Y_{i}+A_{2, i} Y_{i}^{2}
$$

where $A_{0, i}, A_{1, i}$, and $A_{2, i}$ were curve fitting constants, while $A_{0, i}$ equaled the segmentaverage wall temperature $T_{w, i}$. For single-phase cases, the fluid temperature was determined from a series of energy balances. Fluid temperatures were calculated at the position of the measuring thermocouples, at the midpoint of each measuring segment. In condensation, a linear pressure drop was assumed, as saturation temperatures typically changed by less than $1{ }^{\circ} \mathrm{C}$, and the fluid temperature was calculated from the pressure at each measuring segment.

For single-phase validation, the measured test section enthalpy loss was compared to overall energy balance obtained through the gradient method,

$$
\dot{Q}_{g}=\dot{Q}_{\text {header,inlet }}+\dot{Q}_{1}+\dot{Q}_{2}+\dot{Q}_{3}+\dot{Q}_{\text {header,outlet }}
$$

where $\dot{Q}_{g}$ was the total heat transfer rate from the copper block, $\dot{Q}_{\text {header,inlet, }}$ and $\dot{Q}_{\text {header,outlet }}$ were the heat transfer rates from the headers, and $\dot{Q}_{1}, \dot{Q}_{2}$, and $\dot{Q}_{3}$ were the segment-averaged heat transfer rates. As the headers were not adiabatic, incoming fluid was cooled in the header according to

$$
\dot{Q}_{\text {header,inlet }}=h_{\text {inlet }} A_{\text {header }}\left(T_{w, 1}-T_{f, 1}\right)
$$

where $\dot{Q}_{h, \text { inlet }}$ was the header heat transfer rate, $h_{\text {inlet }}$ was the inlet header heat transfer rate, estimated by numerical simulations to be twice the second measuring segment's heat transfer coefficient, $A_{\text {header }}$ was the area of the header specific to the geometry, and $\left(T_{w, 1}-T_{f, 1}\right)$ was the wall-to-fluid temperature difference in the first segment. The header heat transfer rate was incorporated into a series of energy balances and used to calculate segment-averaged qualities for condensing flows.

\subsection{Uncertainties}


The propagation of uncertainties for the reduced data followed standard methods [20], and a detailed description of the analysis can be found in Derby [19]. Thermocouples were calibrated against a reference thermometer (accuracy $0.05{ }^{\circ} \mathrm{C}$ ), with a resulting uncertainty of $\pm 0.2{ }^{\circ} \mathrm{C}$. Extrapolated wall temperature uncertainties were estimated to be $\pm 0.3{ }^{\circ} \mathrm{C}$. The uncertainty in the temperature gradient, $w_{g}$, was determined by an equation developed by Kedzierski and Worthington [17],

$$
w_{g}=\sqrt{w_{T i}^{2}+\left(\frac{q^{\prime \prime} D}{6 k}\right)^{2}} \sqrt{\frac{1}{\sum_{i=1}^{N}\left(y_{i}-\bar{y}\right)^{2}}}
$$

where $w_{T i}$ was the temperature sensor uncertainty of $\pm 0.2^{\circ} \mathrm{C}, y_{i}$ was the position of the $i$ th thermocouple, and $\bar{y}$ was the average position of the thermocouples. Gradient uncertainties were typically \pm 8 to $15 \%$, although could be as high as $\pm 25 \%$ for single-phase experiments and some third measuring segment measurements at low mass flow rates, where the lowest temperature gradients were encountered.

To measure mass flow rates, a bank of four rotameters was calibrated for R134a. Uncertainties for mass flow rate were less than $\pm 5 \%$, except for the $G=300 \mathrm{~kg} / \mathrm{m}^{2} \mathrm{~s}$, where the mass flow rate uncertainty was $\pm 8 \%$ because that flow rate used a lower range of the rotameter.

The pre-heater and test section were insulated to prevent ambient heat loss, as the refrigerant was at a higher temperature than room temperature. A heat loss versus temperature relationship was obtained for the pre-heater through single-phase experiments and two-phase experiments, where the fluid entered the pre-heater subcooled and exited superheated. Electrical data were compared to fluid energy balances. The uncertainty in the pre-heater heat losses was assumed to be $\pm 0.5 \mathrm{~W}$ from the resulting data. 
Another factor that influenced quality was the assumed inlet header heat transfer coefficient, obtained in simulations to be twice that of the center measuring segment's heat transfer coefficient. Thus, a conservative uncertainty of $\pm 25 \%$ was assumed for the inlet header heat transfer coefficients. Uncertainties in quality, highest for the third measuring segment, were less than \pm 0.05 . Ultimately, uncertainties in condensation heat transfer coefficients range from \pm $10 \%$ to $\pm 20 \%$.

\section{Results and Discussion}

\subsection{Single-phase validation}

Single-phase validation experiments compared heat transfer rates obtained from a refrigerant energy balance to those from the temperature gradient in the copper (Equation 3). The energy balances typically agreed within $<5 \%$, with the largest disagreement of $8 \%$ in the square test section. This excellent agreement showed the well-insulated test sections were measuring appropriate heat fluxes, and that the assumptions of header heat transfer coefficients from simulations were reasonable.

Single phase Nusselt numbers were calculated for each of the three measuring segments for comparison with the correlation by Gnielinski [21]. To account for the developing flow in the entrance region, heat transfer coefficients in the first segment were corrected using a correction factor developed by Al-Arabi [22]. As shown in Figure 5, the single-phase heat transfer coefficients changed with Reynolds number to the power of 1.08 for the square channels, 1.21 for the triangular channels, and 1.16 for the semi-circular channels, close to the power of one used in the Gnielinski [21] correlation. Additionally, higher heat transfer coefficients were measured than predicted. Since these Reynolds numbers were at the lower end of the correlation's range, and the Gnielinski [21] correlation was not developed for the micro/mini- 
scales and three-side cooling, a higher value of Nusselt number was determined to be reasonable. The larger scatter in the semi-circular data may be explained by lower heat transfer rates and increasing uncertainties in the temperature gradient and heat transfer coefficient. Good agreements in Nusselt number and energy balance showed this approach was valid for determining the condensation heat transfer coefficient.

\subsection{Condensation data}

Condensation studies were conducted to examine the impact of mass flux, quality, heat flux, saturation pressure, and channel shape on condensation heat transfer coefficients. The data were compared to macro- and mini-scale condensation correlations.

\subsubsection{Effect of mass flux and quality}

For all test sections, the heat transfer coefficients increased with increasing mass flux and quality (Figure 6). These trends makes physical sense, as higher mass fluxes imply higher velocities, and the heat transfer coefficient scales with velocity. Quality changes in each measuring segment were kept under $15 \%$ for mass fluxes of $150 \mathrm{~kg} / \mathrm{m}^{2} \mathrm{~s}$ or higher and quality changes ranged between 20 to $30 \%$ for mass flux of $75 \mathrm{~kg} / \mathrm{m}^{2} \mathrm{~s}$. An upper limit of $100{ }^{\circ} \mathrm{C}$ was applied to the pre-heater temperatures, so a limited quality range was available at higher mass fluxes to prevent pre-heater over-heating. As the uncertainty in quality is highly dependent on the uncertainty in the mass flow rate, the uncertainties in quality at flow rates of $300 \mathrm{~kg} / \mathrm{m}^{2} \mathrm{~s}$ are higher than other mass fluxes because of the rotameter uncertainty at that point.

Shin and Kim [12] and Matkovic et al. [10] found a weak dependence of condensation heat transfer coefficients on quality at mass fluxes lower than $100 \mathrm{~kg} / \mathrm{m}^{2} \mathrm{~s}$ and at 100 and $200 \mathrm{~kg} / \mathrm{m}^{2} \mathrm{~s}$, respectively. However, heat transfer coefficients in Figure 6 vary significantly with quality at a 
mass flux of $75 \mathrm{~kg} / \mathrm{m}^{2} \mathrm{~s}$, from around $1000 \mathrm{~W} / \mathrm{m}^{2} \mathrm{~K}(x=0.1)$ to roughly $3000 \mathrm{~W} / \mathrm{m}^{2} \mathrm{~K}(x=0.75)$. Matkovic et al. [10] postulated that the lack of heat transfer coefficient dependence on quality was either due to experimental uncertainties or an effect of the relative magnitude of surface tension, shear, and gravity forces. The strong dependence of heat transfer coefficients on quality at low mass flow rates in the present study suggests that, experimental uncertainties may have contributed to the observed trends in these previous studies.

\subsubsection{Effect of saturation pressure}

Experiments were conducted at two nominal saturation pressures, $887.5 \mathrm{kPa}$ and $1176 \mathrm{kPa}$, corresponding to saturation temperatures of $35^{\circ} \mathrm{C}$ and $45^{\circ} \mathrm{C}$, respectively. System pressure was controlled via a bladder accumulator. Data from the square test section are shown in Figure 7 without uncertainty bars for clarity; the findings were similar for the other shaped channels. These data show system pressure and temperature does not have a significant effect on condensation of R134a, consistent with the work of Agarwal and Garimella [5].

\subsubsection{Effect of heat flux}

By controlling coolant temperature and maintaining the refrigerant at a saturation temperature of approximately $34{ }^{\circ} \mathrm{C}$, condensation heat flux was varied by a factor of two. Because the coolant temperature was controlled to the nearest degree Celsius, the heat fluxes shown in Figure 8 were for the stated value $\pm 2000 \mathrm{~W} / \mathrm{m}^{2}$. All experiments for heat flux were conducted at a mass flow rate of $300 \mathrm{~kg} / \mathrm{m}^{2} \mathrm{~s}$ and at three average qualities, nominally $0.2,0.35$ and 0.5. The lowest flux was not obtainable for the semi-circle test section, as its different cross sectional area dictated the lowest mass flow rate, thus lowering segment heat transfer rate. No effect of heat flux was observed in this study, despite the factor of two changes in heat flux. Many experimental setups utilizing fluid-to-fluid heat exchangers made heat flux studies 
difficult. Shin and Kim [12], compared an electrically heated test section to a condensing test section and also found no effect of heat flux. Baird et al. [13] reported a significant impact of heat flux, especially at high qualities. Additionally, the observed heat flux effect could be an artifact of thermoelectric cooler behavior. From this study, however, it is concluded that heat flux does not have a significant effect on condensation heat transfer at least under the conditions studied.

\subsubsection{Effect of channel shape}

Square, triangle, and semi-circle channels with hydraulic diameters of $1 \mathrm{~mm}$ were selected for comparison of the effect of channel shape (and, thus, surface tension), on condensation heat transfer. The particular geometry allows for comparison with the numerical work of Wang and Rose [15,23]. Experiments were conducted at four mass fluxes, 75, 150, 300, and $450 \mathrm{~kg} / \mathrm{m}^{2} \mathrm{~s}$ for the three geometries (Figure 9). At the two lower mass fluxes, there is possible enhancement of the square and triangle geometries due to surface tension effects at higher qualities as compared to the semi-circle test section, yet experimental uncertainties prevent definitive conclusions. The results for a mass flux of $300 \mathrm{~kg} / \mathrm{m}^{2}$ s (Figure 9-c) are somewhat unexpected, with the triangle performing lower, beyond the limits of experimental uncertainties, at qualities greater than 0.5. There is no ready description for this behavior; it is possible the triangular channel experienced flooding sooner than the other shaped channels, thus lowering the heat transfer coefficient.

The numerical results of Wang and Rose [15,23] show a strong dependence on channel shape, yet only a possible dependence was shown experimentally at low flow rates and high qualities. This may be explained by different boundary conditions. The numerical work was uniformly cooled, while the experiment was cooled on three sides and insulated on the top side. Wang and Rose [23] observed in square channels that the thinnest liquid film was at the top 
surface, even at low qualities $(x=0.18)$, thereby increasing area-averaged heat transfer coefficients. However, the top surface present in the experiment is adiabatic, and the circumferential averaged heat transfer coefficient does not benefit from this liquid thinning. At low flow rates and high qualities, the liquid film thinning may have an effect in the experiment as the film is thin under these conditions, but as conditions change, the thinnest liquid film may develop on the adiabatic top surface. Therefore, the effect of gravity, albeit low, may explain the differences in condensation heat transfer coefficients between the numerical work of Wang and Rose $[15,23]$ and the experimental work in the present study.

\subsection{Comparison with Correlations}

The data are compared to six existing condensation correlations developed for both the miniand macro-scale. The correlations serve as tools for general comparison; specific comparisons are not possible, as the following correlations were developed for uniformly cooled circular and non-circular tubes, whereas the boundary conditions in the current experiment are three-sided cooling. However, laminar flow illustrates that the difference in Nusselt numbers based on threeside and four-sided boundary conditions are negligible. For a square duct with constant temperature boundary conditions, the Nusselt number varies from 2.970 (four walls transferring heat) to 3.018 (three sides transferring heat, one adiabatic side), according to Shah [24]. This difference of $1.6 \%$ is less than experimental uncertainties, thus making comparisons with existing mini- and macro-scale condensation correlations informative.

The Akers et al. [1] correlation utilized an equivalent liquid mass flux and equivalent liquid shear stress for macro-scale condensing flow in order to use a single-phase type correlation. Shah [25] developed a curve-fit correlation with 21 sets of data at varying conditions. The correlation was then expanded in Shah [26], which included multiple regimes and incorporated newer 
refrigerants, a wider range of parameters, and lower flow rates. Bandhauer et al. [9] and Agarwal et al. [16] developed a piecewise correlation for mini-and micro-scale condensation for circular and non-circular channels, respectively. The correlations feature an annular model similar to Traviss et al. [27], and then a mist flow correlation identical to the macro-scale one developed by Soliman [28].

Correlation effectiveness was assessed using mean average error, defined as

$$
M A E=\frac{1}{N} \sum_{i=1}^{N}\left|\frac{h_{\text {pred }}-h_{\text {exp }}}{h_{\text {exp }}}\right|
$$

where $h_{\text {pred }}$ was the heat transfer coefficient predicted by the correlation, $h_{\text {exp }}$ was the experimentally determined heat transfer coefficient, and $N$ is the number of data points in a given set. Overall MAEs are presented for square, triangular and semi-circular channels at a saturation temperature of $35^{\circ} \mathrm{C}$ (Table 1). All correlations yield the largest deviation at the lowest mass flux of $75 \mathrm{~kg} / \mathrm{m}^{2} \mathrm{~s}$, and the deviation decreases as mass flux increases, likely because this lowest mass flux has higher uncertainties and is lower than those used to develop the correlations. Also, it is shown that the Shah [25] and Shah [26] correlations yield near identical results, as a viscosity correction factor was the only difference for these data at these flow rates and qualities. Flow rates and qualities were high enough such that all data were in a regime in the Shah [26] correlation that was very similar in form to the Shah [25] correlation; otherwise, there might have been significant differences between the correlations. Additionally the Akers et al. [1] correlation consistently overpredicted the data.

The experimental versus predicted data depicted in Figure 10, for all mass fluxes at saturation temperature of $35{ }^{\circ} \mathrm{C}$. For clarity, the Akers et al. [1] correlation was excluded because it consistently and significantly overpredicted the data, and the Shah [25] correlation was omitted 
because its results were comparable to the Shah [26] correlation. Overall, the macro-scale Shah [26] correlation best predicted the condensation heat transfer coefficients for all shape, although it did overpredict at higher heat transfer coefficients. The mini-scale annular heat transfer regimes of Bandhauer et al. [9] and Agarwal et al. [16] correlations captured the appropriate trends, but not magnitudes, with mean average errors of around $40 \%$. A deficiency of these correlations was at low mass fluxes of 75 and $150 \mathrm{~kg} / \mathrm{m}^{2} \mathrm{~s}$, these correlations did not always return a value when the argument of a natural log term became negative.

The prediction of Soliman [28] improved as mass flux increased. Weber numbers started exceeding 20 - the threshold of mist flow - for $14-27 \%$ of the data at a mass flux of $300 \mathrm{~kg} / \mathrm{m}^{2} \mathrm{~s}$, and for $60-70 \%$ of the data at a mass flow of $450 \mathrm{~kg} / \mathrm{m}^{2} \mathrm{~s}$. At increasing mass flux and Weber number, the flow is more likely to be in the mist regime, thus, the Soliman [28] correlation had better agreement as mass flux increased.

Overall, the macro-scale Shah [26] correlation, a modification of the Shah [25] work, best predicted the data, with an average MAE of 20 to $30 \%$ for all test sections. This macro-scale correlation well predicted the mini-scale data because, due to the boundary conditions, surface tension enhancement was not observed. Another macro-scale correlation by Akers et al. [1] grossly overpredicted the data. All correlations had poor prediction at the lowest mass flux, including the Bandhauer et al. [9] and Agarwal et al. [16] correlations. For the mist flow model developed by Soliman [28], agreement improved at higher mass fluxes because, according to the modified Weber number, the flow more frequently was in the mist regime.

\section{Conclusions}


In order to obtain condensation heat transfer coefficients with low uncertainties, a measurement method was developed that utilized conduction in a copper block to measure condensation heat fluxes and wall temperatures. Three channel geometries (square, triangle, semi-circle) with hydraulic diameters of $1 \mathrm{~mm}$ were machined to facilitate comparison of channel shape and condensation physics due to surface tension. Single-phase experiments validated the experimental apparatus and procedures, with good agreement between single-phase heat transfer coefficients and the Gnielinski (1995) correlation.

Condensation heat transfer coefficients were obtained from the three geometries over ranges of mass flux, quality, pressure, and heat flux and were strongly dependent on mass flux and quality but not on heat flux and saturation pressure. Other researchers have found no quality dependence at low mass fluxes, which may be an artifact of high heat transfer coefficient uncertainties at low flow rates in their experimental setups.

A key parameter in this study was the comparison of square, triangular, and semi-circular channel geometries with the same hydraulic diameter of $1 \mathrm{~mm}$. Numerical studies by Wang and Rose $[15,23]$ found significant condensation heat transfer enhancement through surface tension at the millimeter scale. Generally, no appreciable differences were found between channel shapes in this study. The lack of surface tension effect was perhaps in part influenced by the three-sided cooling boundary conditions.

The Shah [26] correlation best predicted the data, with an average MAE between 20 to 30\% for all test section geometries. Although it offered the lowest $M A E$, it should be noted that it overpredicted higher condensation heat transfer coefficients.

\section{Acknowledgments}


The authors acknowledge the financial support of Office of Naval Research through a MURI grant, Grant No. N00014-07-1-0723 entitled "System-Level Approach for Multi-Phase, Nanotechnology-Enhanced Cooling of High-Power Microelectronic Systems," and a graduate fellowship from the NSF GK12 program, "Building Bridges from High School to Grad School Through Discovery-Based Activities in Energy and the Environment.”

\section{Nomenclature}

$\begin{array}{ll}A_{0, i} & \text { polynomial curve fitting constant, intercept }\left[{ }^{\circ} \mathrm{C}\right] \\ A_{1, i} & \text { polynomial curve fitting constant }\left[{ }^{\circ} \mathrm{C} / \mathrm{m}\right] \\ A_{2, i} & \text { polynomial curve fitting constant }\left[{ }^{\circ} \mathrm{C} / \mathrm{m}^{2}\right] \\ A_{\text {header }} & \text { area of the header }\left[\mathrm{m}^{2}\right] \\ C_{0, i} & \text { y-axis intercept }\left[{ }^{\circ} \mathrm{C}\right] \\ C_{1, i} & \text { slope of the line }\left[{ }^{\circ} \mathrm{C} / \mathrm{m}\right] \\ D_{h} & \text { hydraulic diameter }[\mathrm{m}] \\ d T / d y_{i} & \text { segment-averaged temperature gradient }\left[{ }^{\circ} \mathrm{C} / \mathrm{m}\right] \\ h_{i} & \text { segment-averaged heat transfer coefficient }\left[\mathrm{W} / \mathrm{m}^{2} \mathrm{~K}\right] \\ h_{\text {inlet }} & \text { inlet header heat transfer coefficient }\left[\mathrm{W} / \mathrm{m}^{2} \mathrm{~K}\right] \\ h_{\text {outlet }} & \text { outlet header heat transfer coefficient }\left[\mathrm{W} / \mathrm{m}^{2} \mathrm{~K}\right] \\ i & \text { the index representing measuring segments } 1,2, \text { and } 3 \\ k & \text { thermal conductivity [W/mK] } \\ L_{s e g, i} & \text { length of the measuring segment }[\mathrm{m}] \\ M A E & \text { mean average error } \\ \dot{Q}_{g} & \text { total heat transfer rate from the gradient method }[\mathrm{W}]\end{array}$




$\begin{array}{ll}\dot{Q}_{\text {header,inlet }} & \text { inlet header heat transfer rate }[\mathrm{W}] \\ \dot{Q}_{\text {header, outlet }} & \text { outlet header heat transfer rate }[\mathrm{W}] \\ q_{i}^{\prime \prime} & \text { channel heat flux }\left[\mathrm{W} / \mathrm{m}^{2}\right] \\ \dot{Q}_{i} & \text { heat transfer rate in each measuring segment }[\mathrm{W}] \\ T_{f, i} & \text { segment-averaged fluid temperature }\left[{ }^{\circ} \mathrm{C}\right] \\ T_{i} & \text { temperature in copper block }\left[{ }^{\circ} \mathrm{C}\right] \\ T_{w, i} & \text { segment-averaged wall temperature }\left[{ }^{\circ} \mathrm{C}\right] \\ W & \text { width [m] } \\ w_{g} & \text { uncertainty in the temperature gradient }\left[{ }^{\circ} \mathrm{C} / \mathrm{m}\right] \\ w_{T i} & \text { uncertainty in temperature }\left[{ }^{\circ} \mathrm{C}\right] \\ x & \text { quality } \\ Y & \text { thermocouple's distance from the bottom of the channel }[\mathrm{m}] \\ y_{i} & \text { position of the ith thermocouple [m] } \\ \bar{y} & \text { average thermocouple position in measuring segment }[\mathrm{m}]\end{array}$

\section{References}

[1] W.W. Akers, H. A. Deans, O.K. Crosser, Condensing heat transfer within horizontal tubes, Chemical Engineering Progress Symposium Series 55 (29) (1959) 171-176.

[2] M.K Dobson, J.C. Chato, Condensation in smooth horizontal tubes, Journal of Heat Transfer, 120 (1998) 193-213.

[3] A. Cavallini, G. Censi, D. Del Col, L. Doretti, G.A. Longo, L. Rossetto, Experimental investigation on condensation heat transfer coefficient inside multi-port minichannels, Proceedings of the First International Conference on Microchannels and Minichannels, Rochester, NY, 2003, pp. 691-698. 
[4] W.W. Wang, T.D Radcliff, R.N Christensen, A condensation heat transfer coerrelation for millimeter-scale tubing with flow regime transition, Experimental Thermal and Fluid Science, 26 (5) (2002) 473-485.

[5] A. Agarwal, S. Garimella, Representative results for condensation measurements at hydraulic diameters 100 microns, Journal of Heat Transfer 132 (2010) 041010-1-041010-12.

[6] J. Fernandez-Seara, F.J. Uhia, J. Sieres, A. Campo, A general review of the Wilson plot method and its modifications to determine convection coefficients in heat exchanger devices, Applied Thermal Engineering 27 (17-18) (2007) 2745-2757.

[7] S. Garimella, T.M. Bandhauer, Measurement of condensation heat transfer coefficients in microchannel tubes, Proceedings of 2001 ASME International Mechanical Engineering Congress and Exposition, New York, NY (2001), pp. 1-7.

[8] R.W. Webb, K. Ermis, Effect of hydraulic diameter on condensation of R-134a in flat, extruded aluminum tubes, Enhanced Heat Transfer 8 (2) (2001) 77-90.

[9] T.M. Bandhauer, A. Agarwal, S. Garimella, Measurement and modeling of condensation heat transfer coefficients in circular microchannels, Journal of Heat Transfer 128 (10) (2006) 10501059.

[10] M. Matkovic, A. Cavallini, D. Del Col, L. Rossetto, Experimental study on condensation heat transfer inside a single circular minichannel, International Journal of Heat and Mass Transfer 52 (9-1) (2009) 2311-2323.

[11] J.S. Shin, M.H. Kim, An experimental study of condensation heat transfer inside a minichannel with a new measurement technique, International Journal of Multiphase Flow 30 (3) (2004) 311-325.

[12] J.S. Shin, M.H. Kim, An experimental study of flow condensation heat transfer inside circular and rectangular mini-channels, Heat Transfer Engineering 26 (3) (2005) 36-44.

[13] J.R. Baird, D.F. Fletcher, B.S. Haynes, Local Condensation Heat Transfer Rates in Fine Passages, International Journal of Heat and Mass Transfer 46 (23) (2003) 4453-4466.

[14] M.M. Derby, H.J. Lee, R.C. Craft, G.J. Michna, Y. Peles, M.K. Jensen, Exploration of experimental techniques to determine the condensation heat flux in microchannels and minichannels, Proceedings of the 14th International Heat Transfer Conference, Washington, D.C., 2010.

[15] H.S. Wang, J.W. Rose, Film condensation in horizontal microchannels: Effect of channel shape, International Journal of Thermal Sciences 45 (12) (2006) 1205-1212.

[16] A. Agarwal, T.M. Bandhauer, S. Garimella, Heat transfer model for condensation in noncircular microchannels, Proceedings of the Fifth International Conference on Nanochannels, Microchannels and Minichannels, Puebla, Mexico, 2007, pp. 117-126. 
[17] M.A. Kedzierski, J.L. Worthington III, 1993, "Design and machining of copper specimens with micro holes for accurate heat transfer measurements,” Experimental Heat Transfer 6 (4), (1993) 329-344.

[18] M. Kedzierski, Enhancement of R123 pool boiling by the addition of hydrocarbons, International Journal of Refrigeration 23 (2) (2000) 89-100.

[19] M. Derby, Condensation heat transfer in square, triangular and semi-circular mini-channels, Master's Thesis, Rensselaer Polytechnic Institute, Troy, NY, 2010.

[20] S.J. Kline, F.A. McClintock, Describing Uncertainties in Single-Sample Experiments, Mechanical Engineering 75 (1) (1953) 3-8.

[21] V. Gnielinski, New method to calculate heat transfer in the transition region between laminar and turbulent tube flow, Forschung im Ingenieurwesen 61 (9) (1995) 240.

[22] M. Al-Arabi, Turbulent heat transfer in the entrance region of a tube, Heat Transfer Engineering 3 (3-4) (1982) 76-83.

[23] H.S. Wang, J.W. Rose, A theory of film condensation in horizontal noncircular section microchannels, Journal of Heat Transfer 127 (2005) 1096-1105.

[24] R.K. Shah, A.L. London, Laminar Flow Forced Convection in Ducts, supplement one, Academic Press, Inc., New York, 1978, pp. 196-213.

[25] M.M. Shah, General correlation for heat transfer during film condensation inside pipes, International Journal of Heat and Mass Transfer 36 (7) (1979) 547-556.

[26] M.M. Shah, An improved and extended general correlation for heat transfer during condensation in plain tubes, HVAC\&R Research 15 (5) (2009) 889-913.

[27] D.P. Traviss, W.M. Rohsenow, A.B. Baron, Forced convection condensation in tubes: A heat transfer correlation for condenser design, ASHRAE Transactions 79 (1972) 157-165.

[28] H.M. Soliman, H. M., 1986, The mist-annular transition during condensation and its influence on the heat transfer mechanism, Int. J. Multiphase Flow 12 (2) (1986) 277-288. 


\section{Figure Captions}

Figure 1 Basic test section design

Figure 2 Channel cross sections all with $1 \mathrm{~mm}$ hydraulic diameter

Figure 3 Condensation loop schematic

Figure 4 Temperature profile from first measuring segment in experiments with square channels, average quality of 0.33

Figure 5 Single-phase validation

Figure 6 Heat transfer coefficients in a) square, b) triangle, c) semi-circle channels with $\mathrm{T}_{\text {sat }}=35$

${ }^{\circ} \mathrm{C}$

Figure 7 Effect of saturation pressure on square channels

Figure 8 Effect of heat flux in a) square b) triangle c) semi-circle channels

Figure 9 Comparison of heat transfer coefficients with respect to channel shape at mass fluxes of

a) $75 \mathrm{~kg} / \mathrm{m}^{2} \mathrm{~s}$ b) $150 \mathrm{~kg} / \mathrm{m}^{2} \mathrm{~s}$ c) $300 \mathrm{~kg} / \mathrm{m}^{2} \mathrm{~s}$ d) $450 \mathrm{~kg} / \mathrm{m}^{2 \mathrm{~s}}$

Figure 10 Comparison with condensation correlations for a) square b) triangle c) semi-circle channels 


\section{Figures}

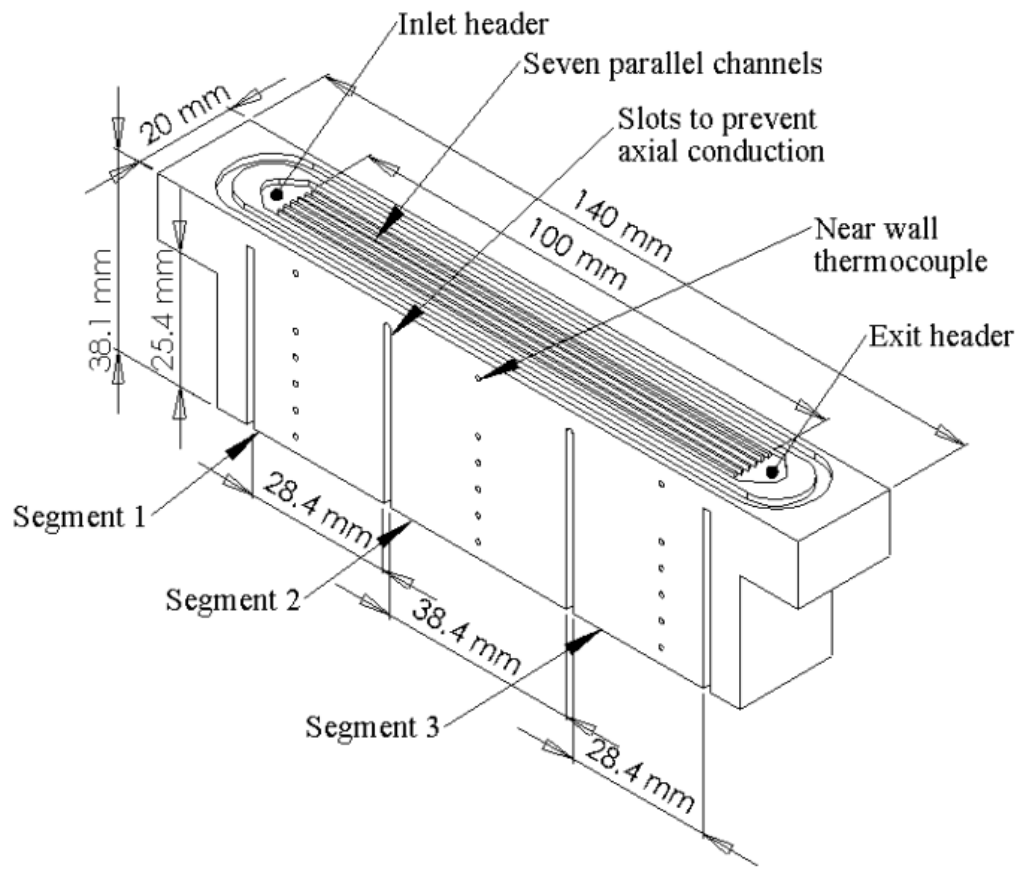

Figure 1 Basic test section design 


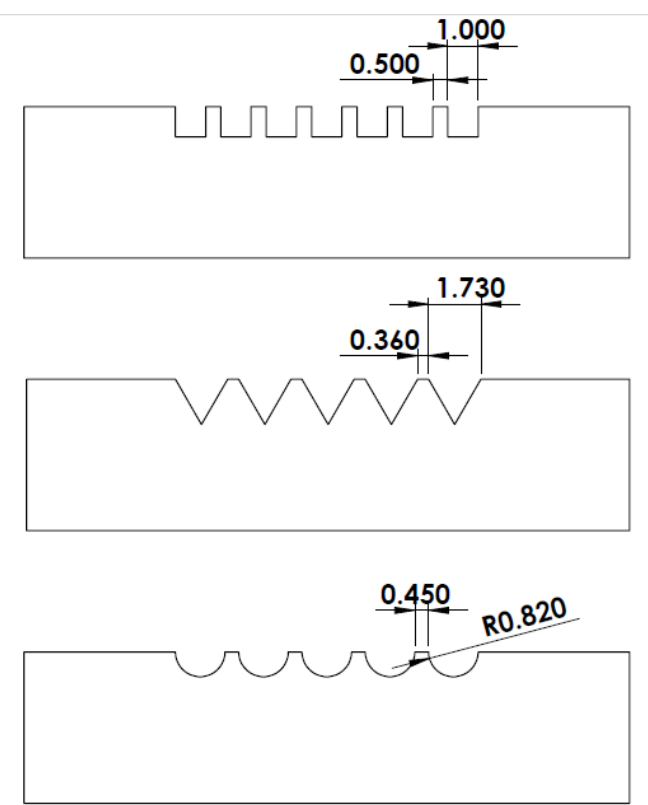

All dimensions in millimeters

Figure 2 Channel cross sections all with $1 \mathrm{~mm}$ hydraulic diameter 


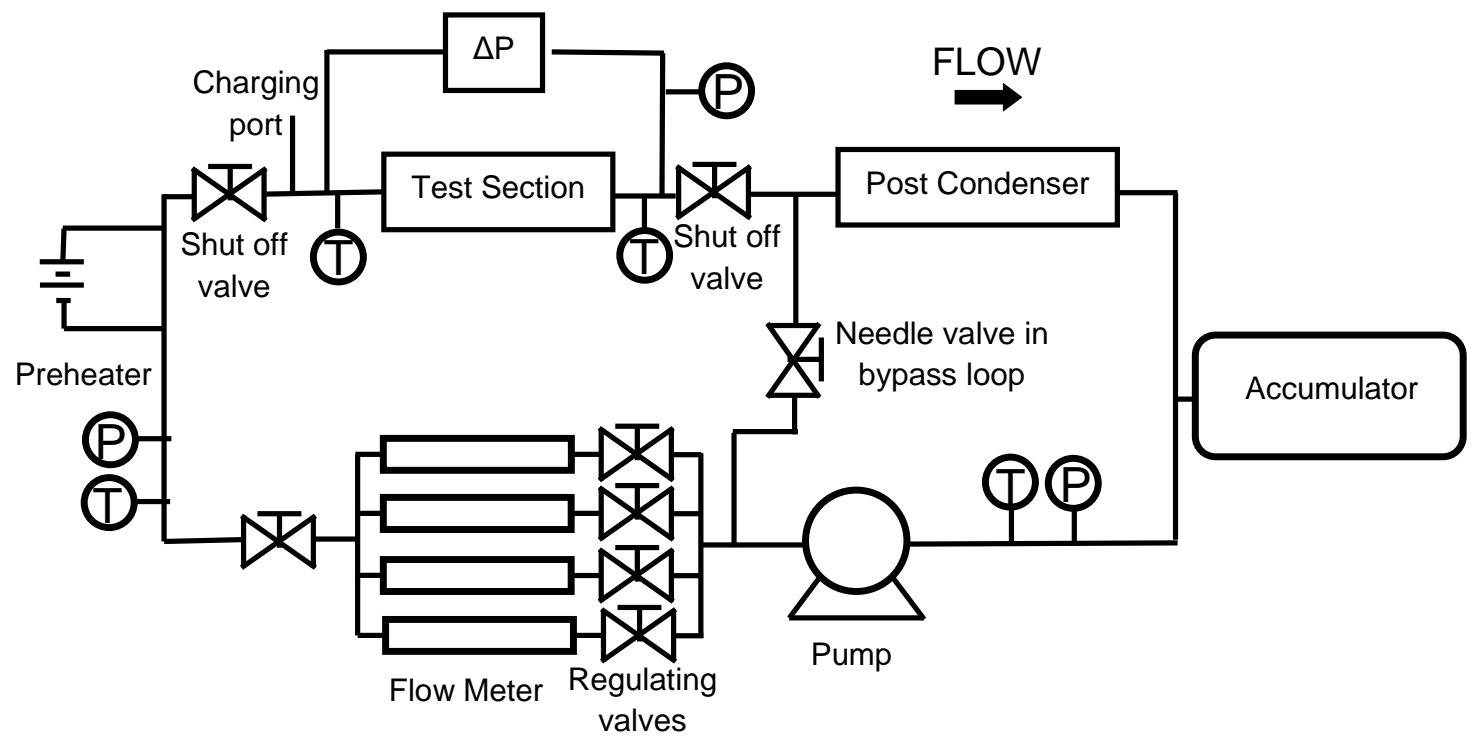

Figure 3 Condensation loop schematic 


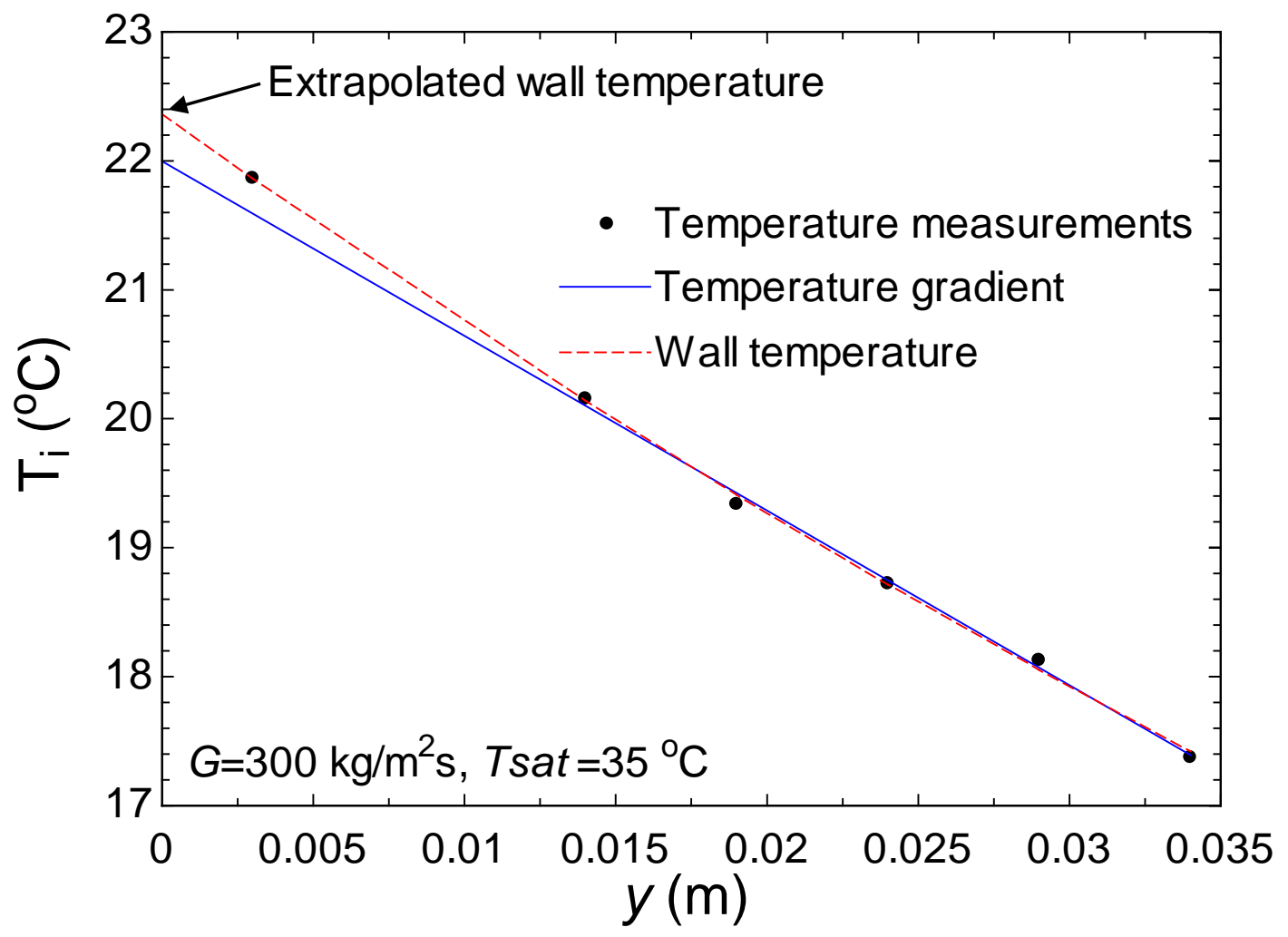

Figure 4 Temperature profile from first measuring segment in experiments with square channels, average quality of 0.33 


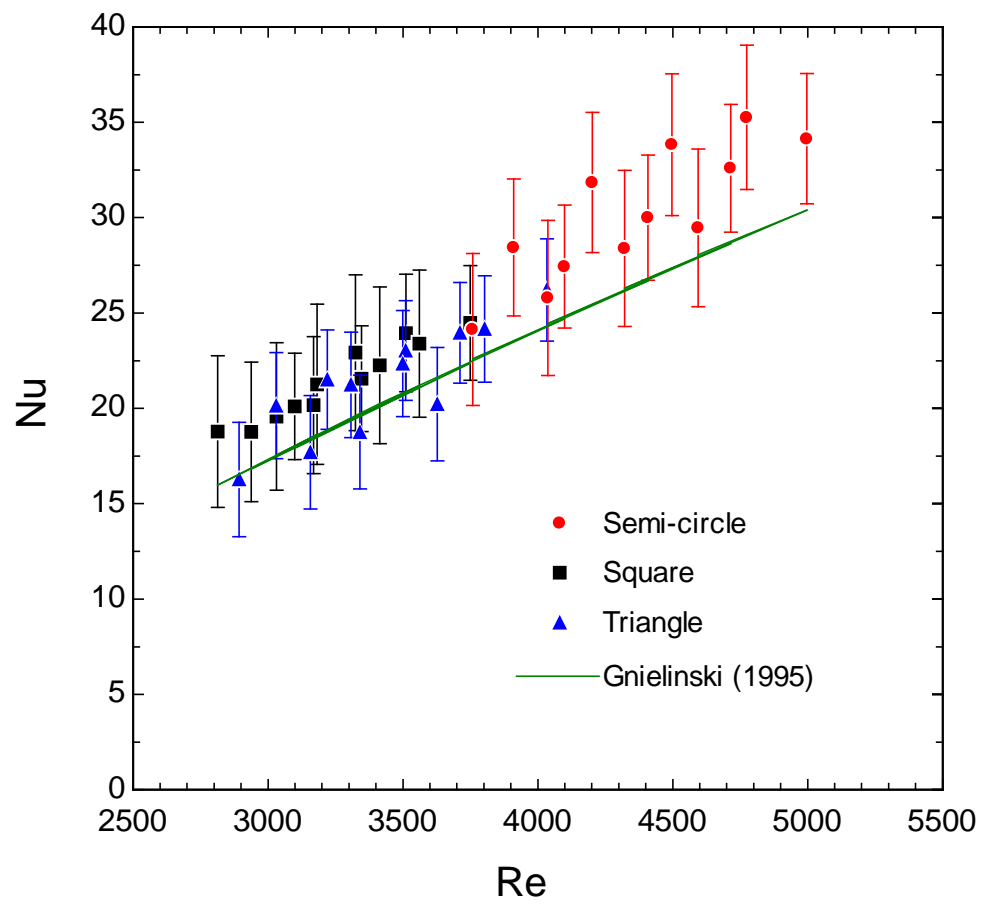

Figure 5 Single-phase validation 


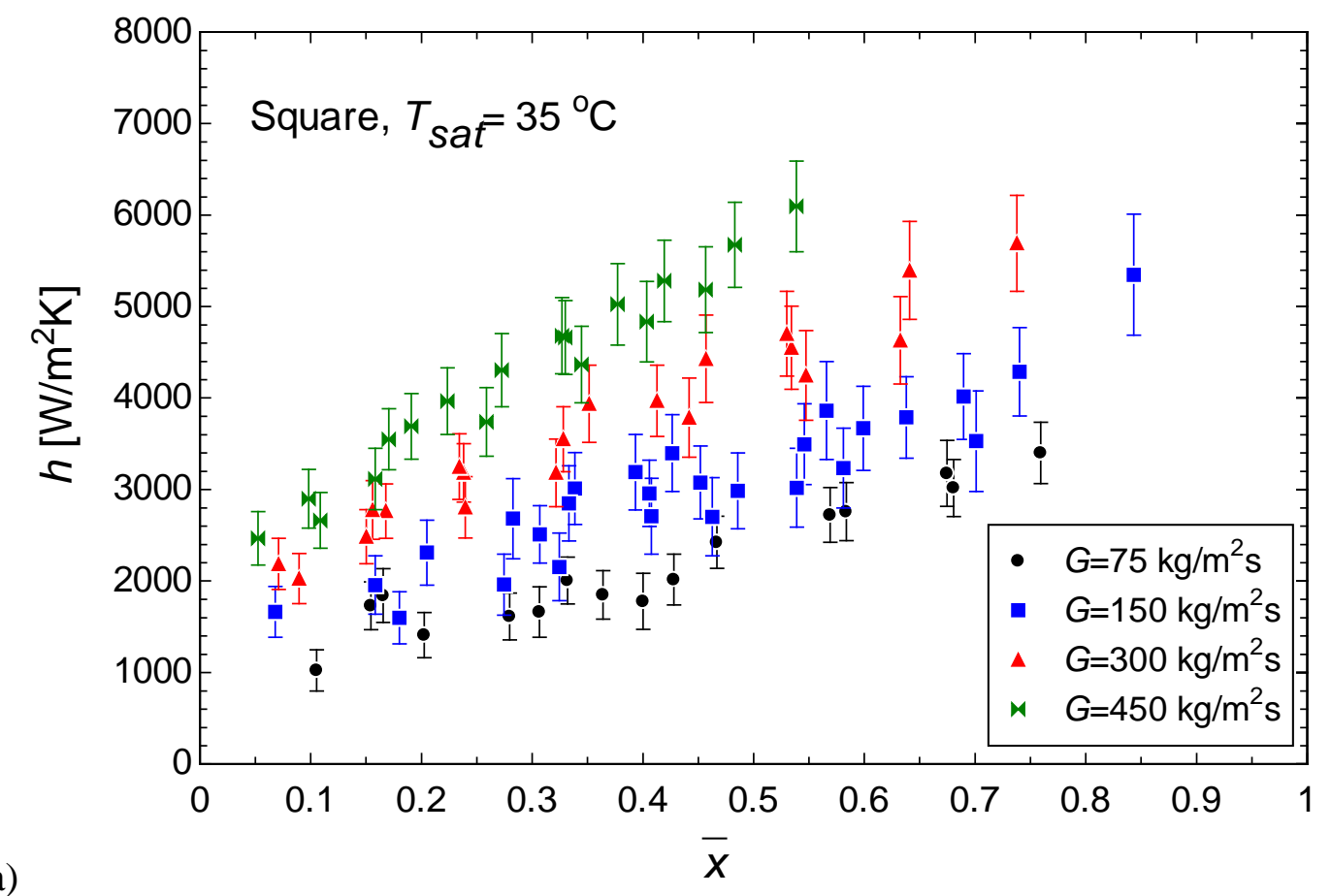

a)

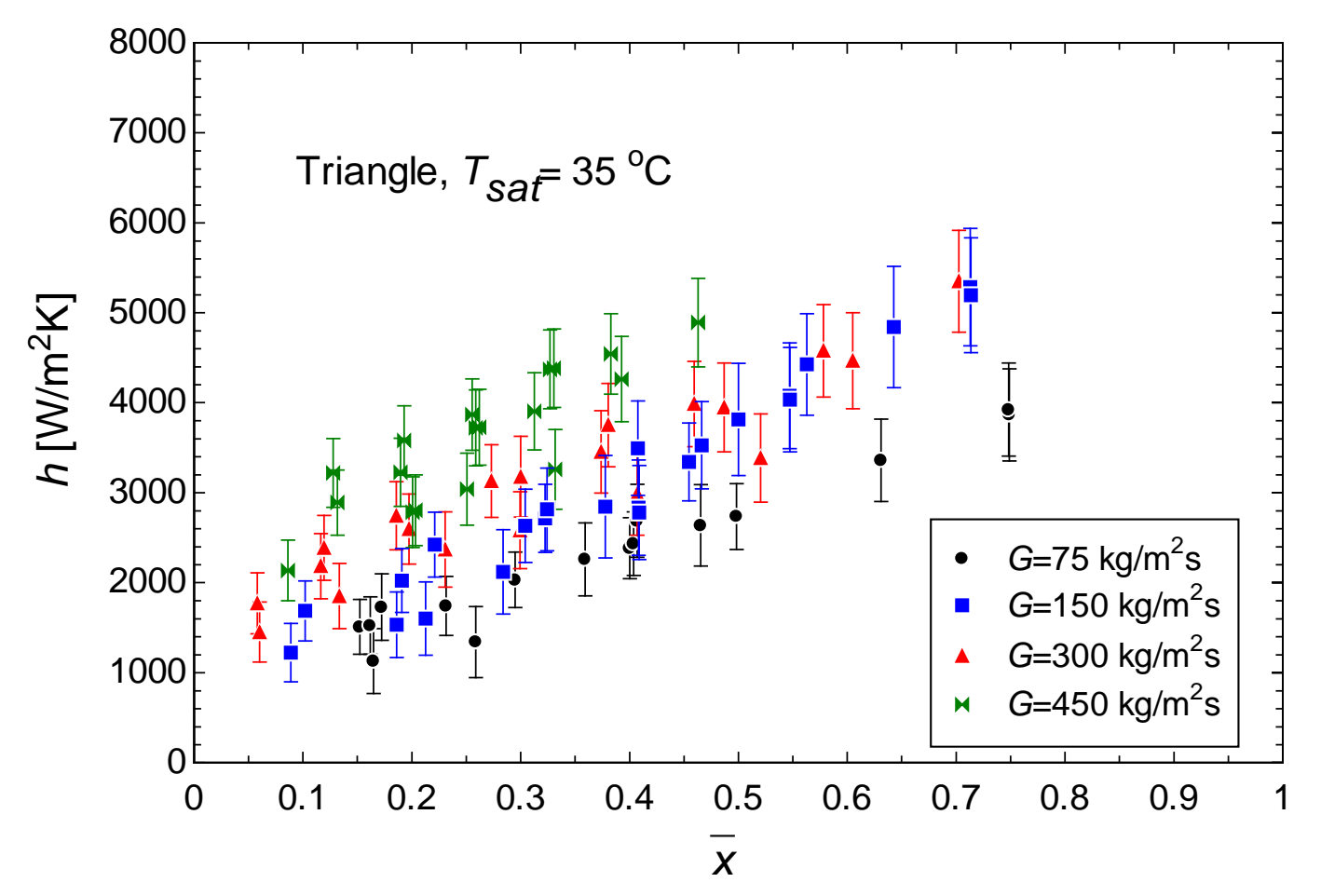




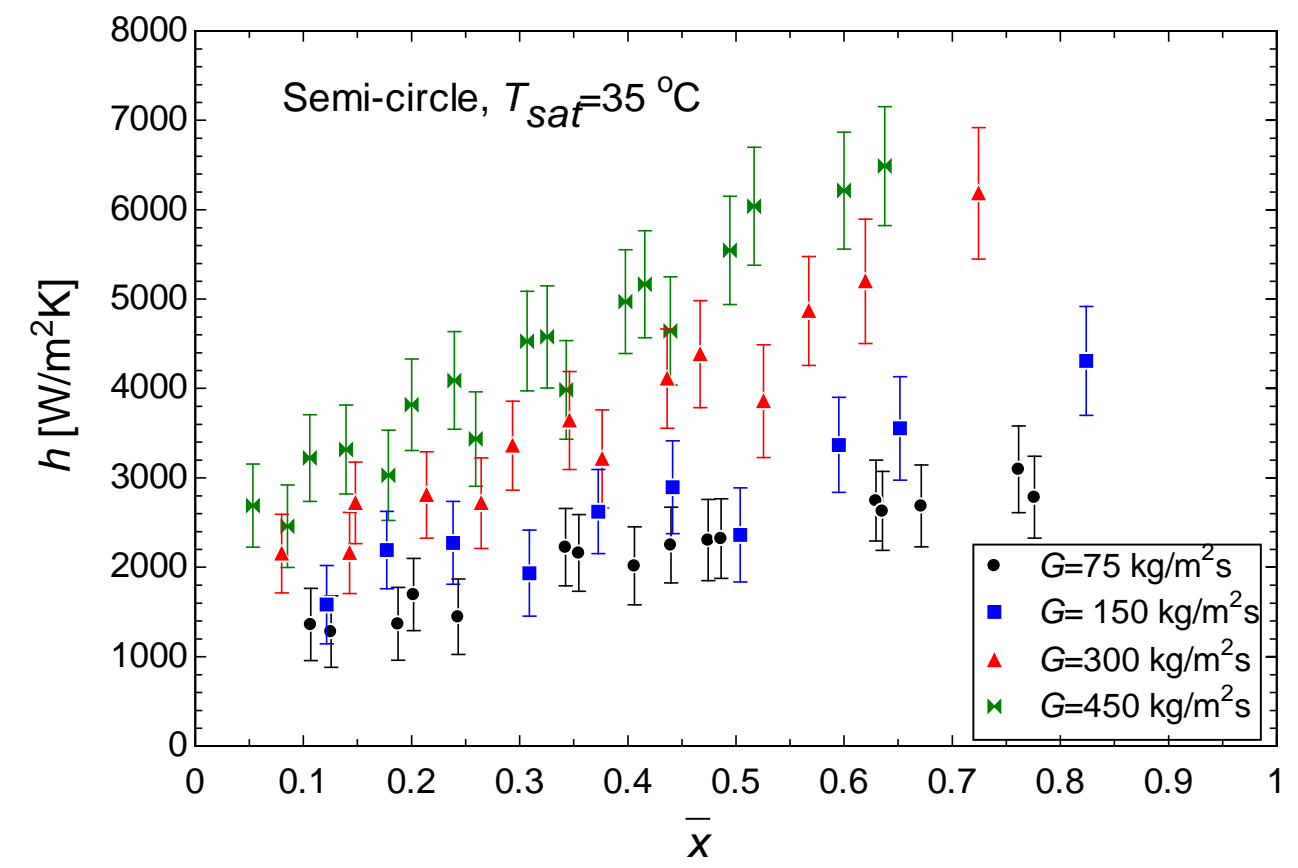

Figure 6 Heat transfer coefficients in a) square, b) triangle, c) semi-circle channels with Tsat= 35 ${ }^{\circ} \mathrm{C}$ 


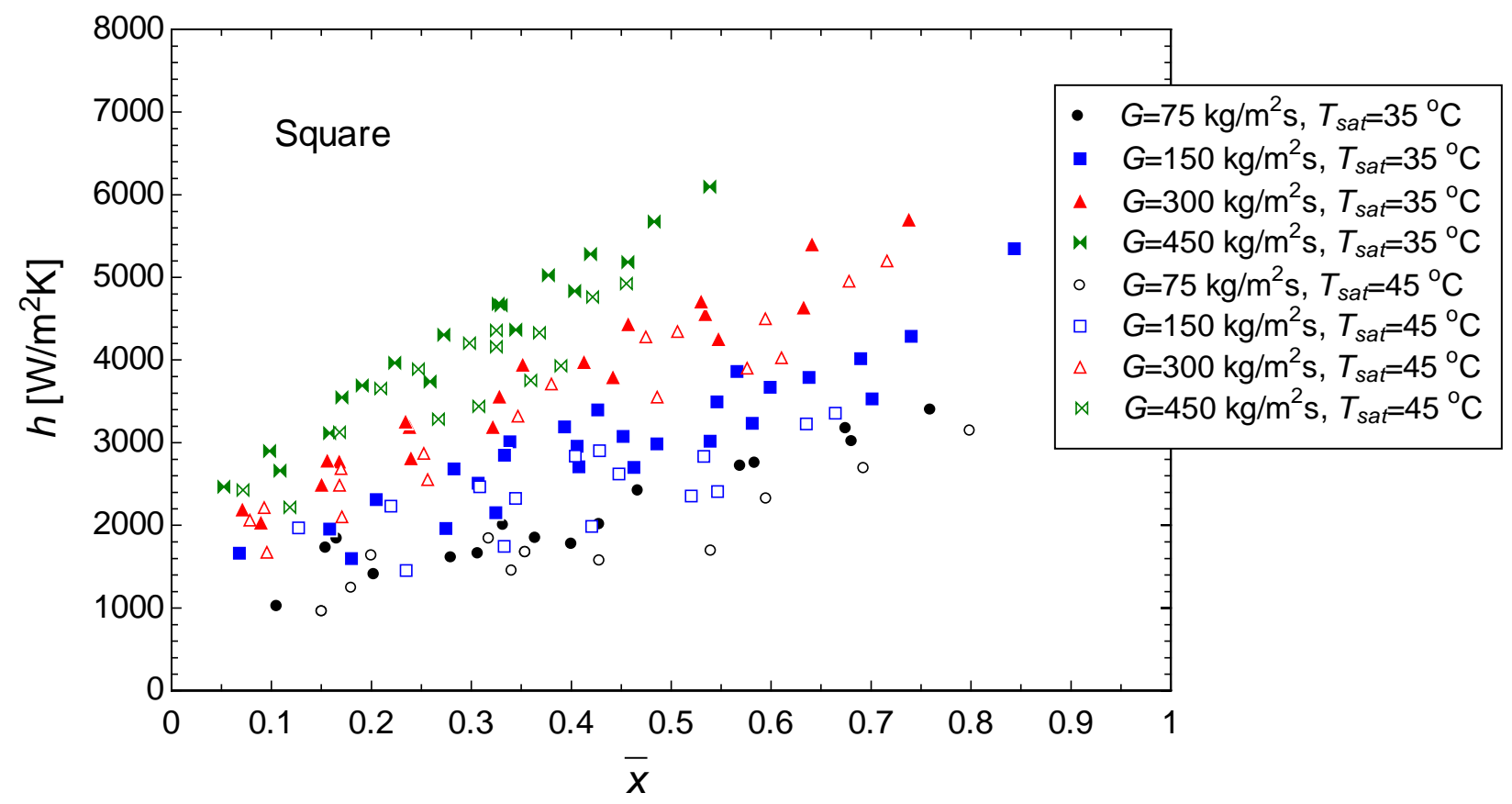

Figure 7 Effect of saturation pressure on square channels 


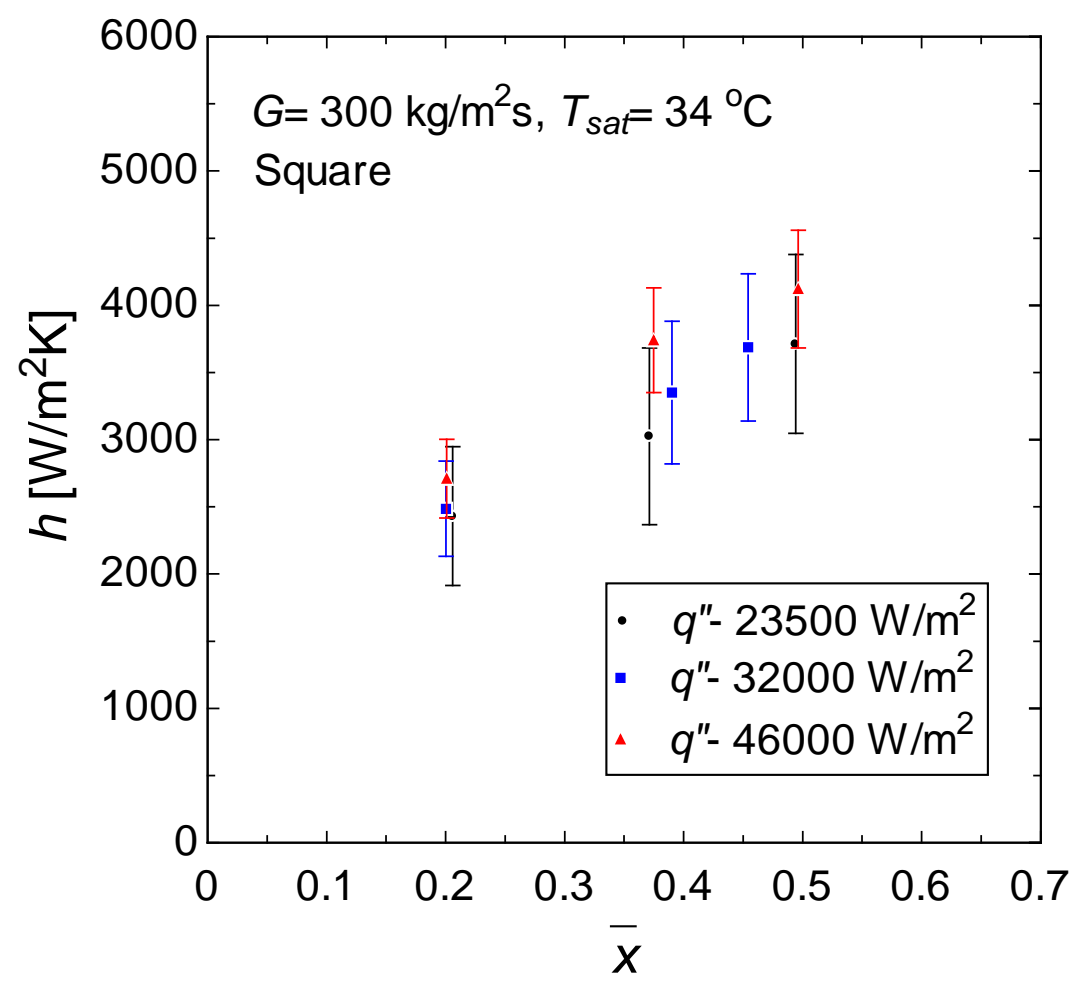

a)

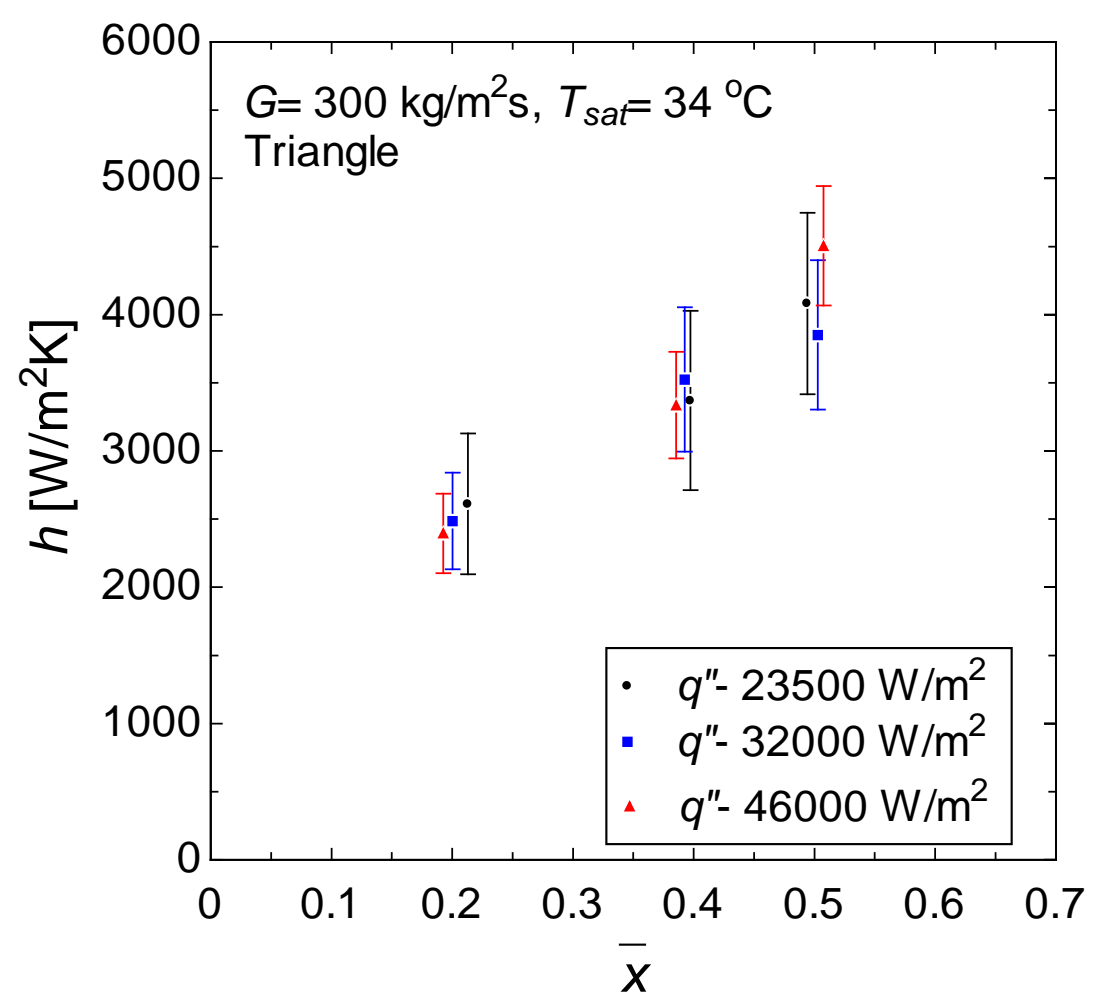

b) 


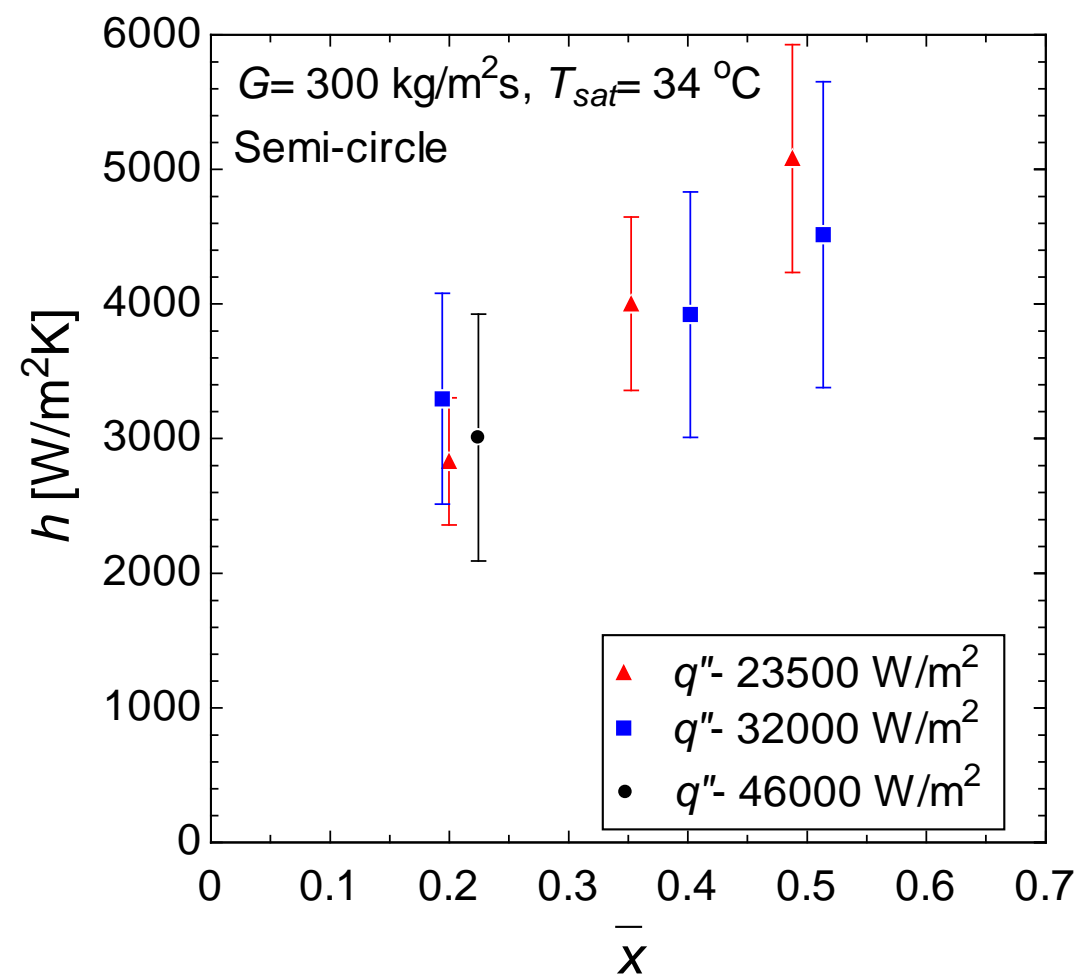

c)

Figure 8 Effect of heat flux in a) square b) triangle c) semi-circle channels 

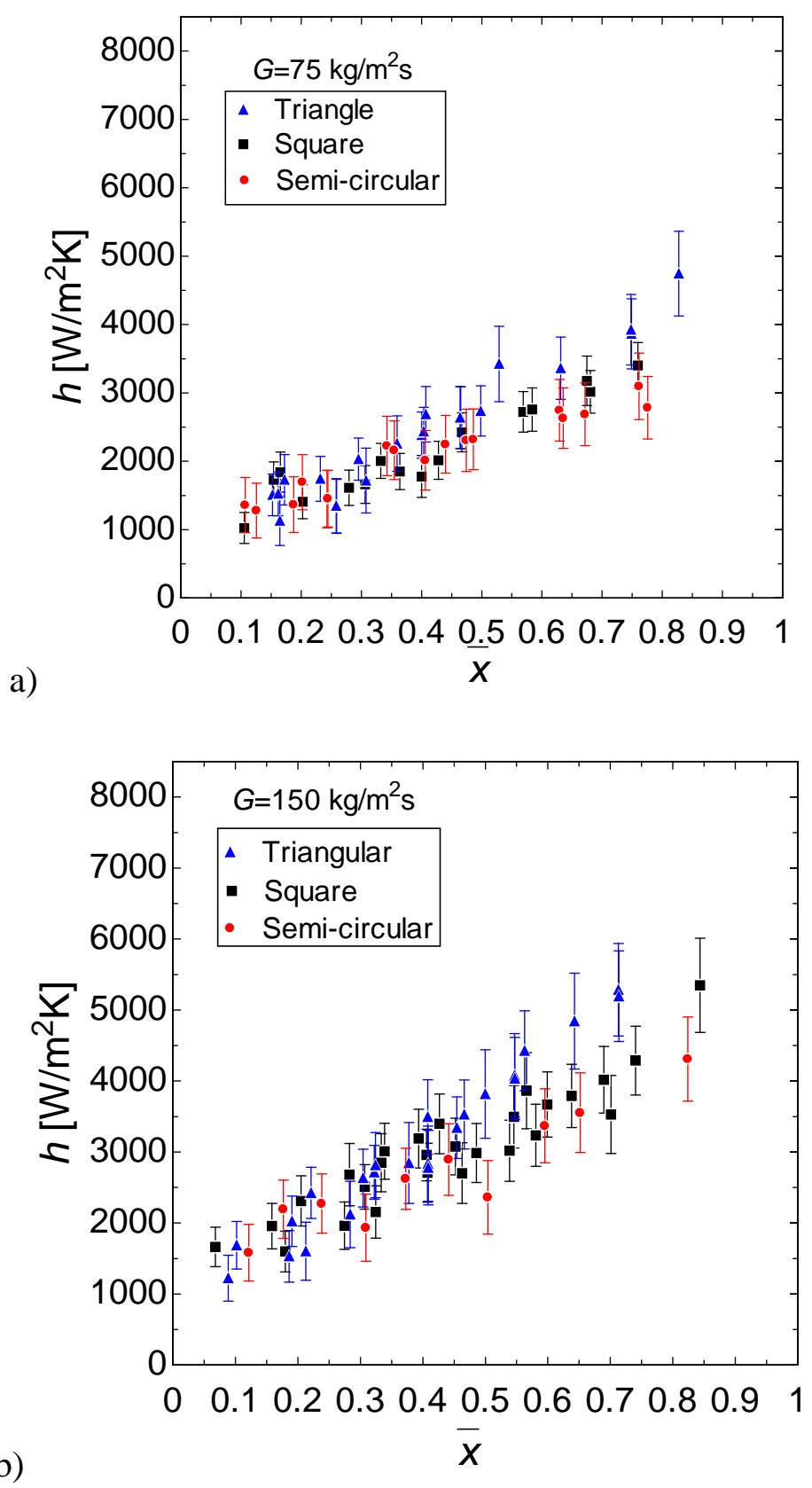

Derby 


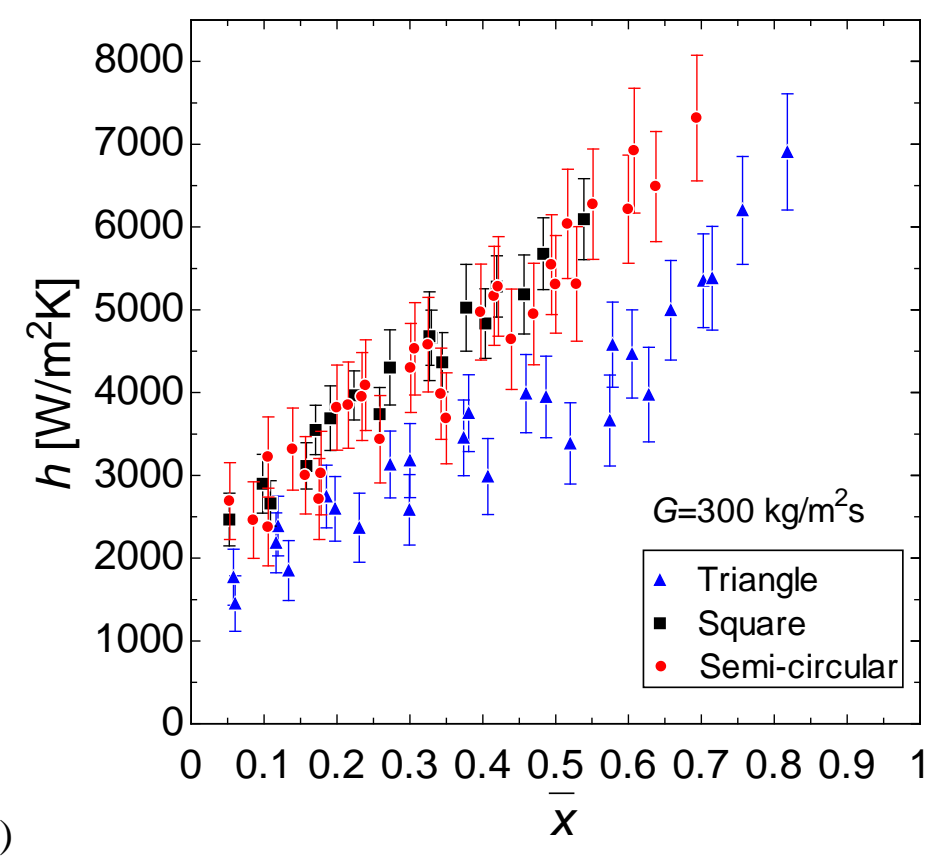

c)

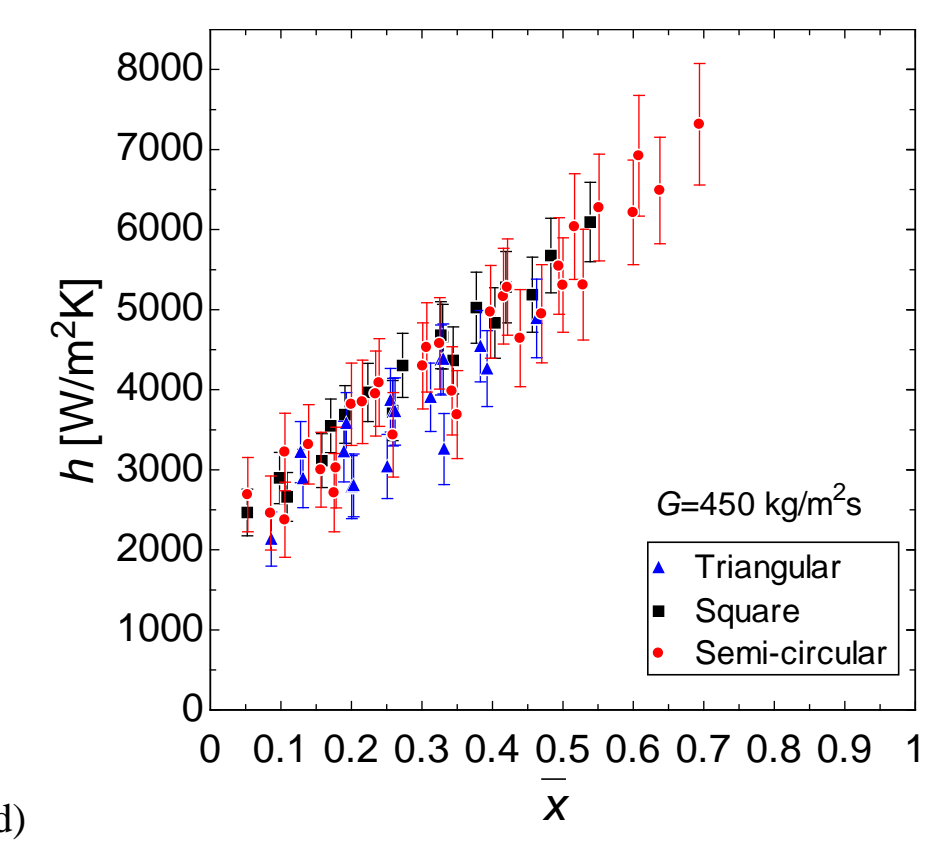

Figure 9 Comparison of heat transfer coefficients with respect to channel shape at mass fluxes of

a) $75 \mathrm{~kg} / \mathrm{m}^{2} \mathrm{~s}$ b) $150 \mathrm{~kg} / \mathrm{m}^{2} \mathrm{~s}$ c) $300 \mathrm{~kg} / \mathrm{m}^{2} \mathrm{~s}$ d) $450 \mathrm{~kg} / \mathrm{m}^{2} \mathrm{~s}$ 

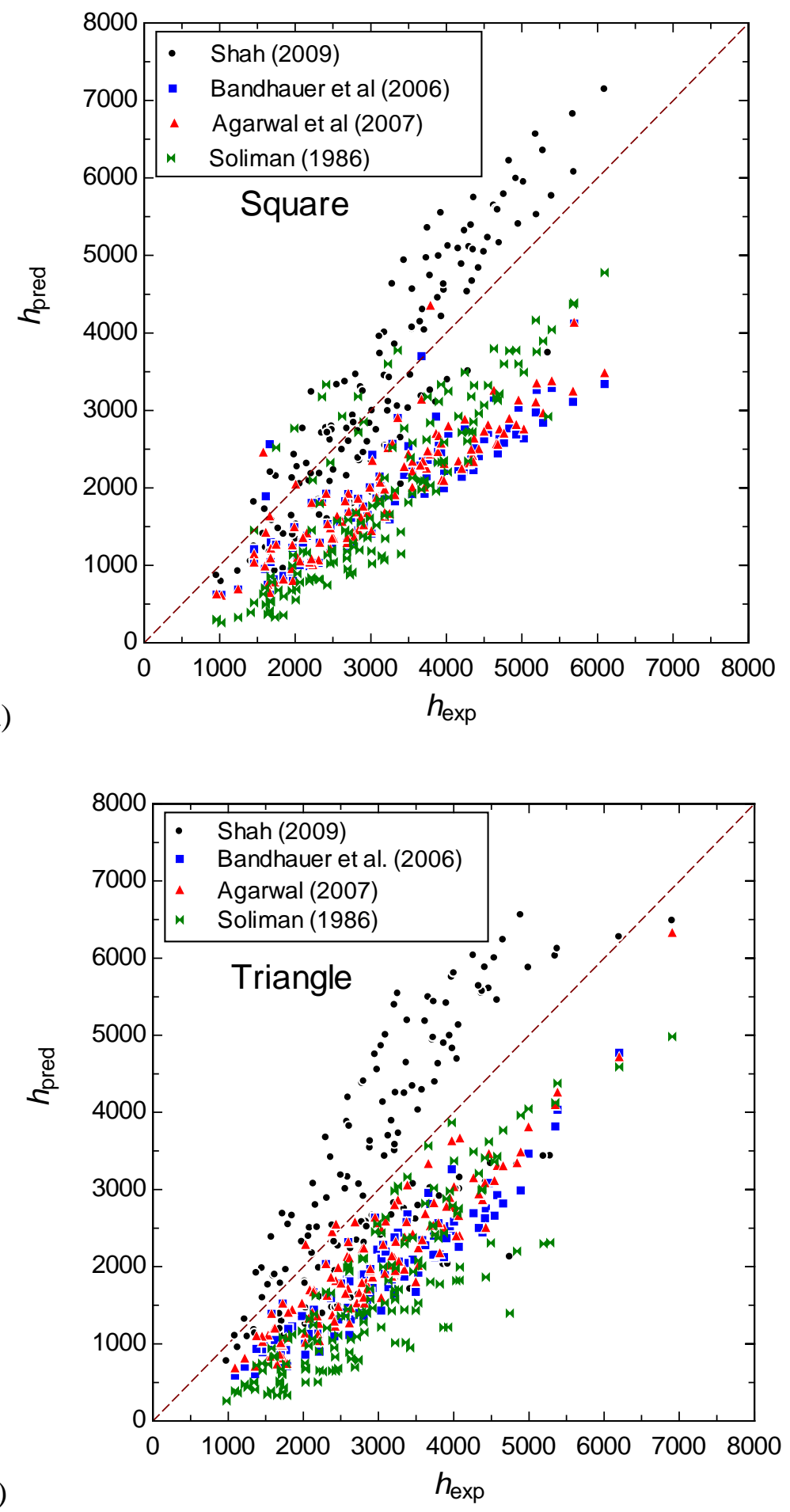

b) 


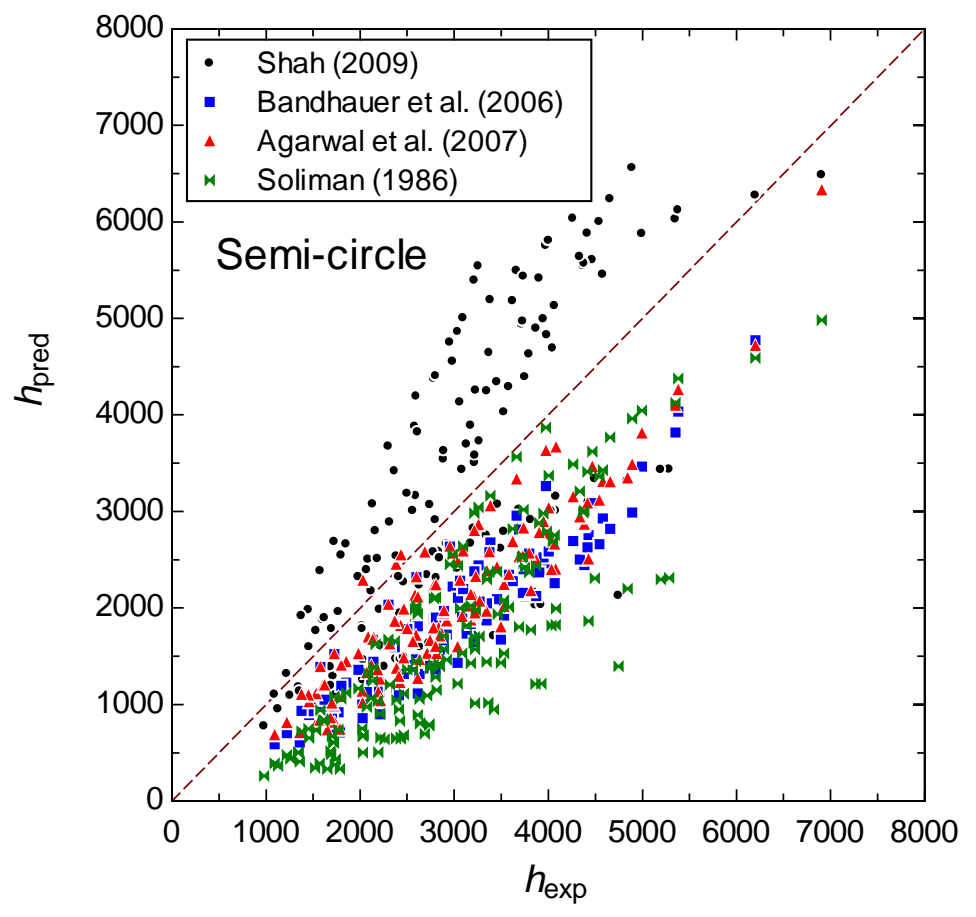

Figure 10 Comparison with condensation correlations for a) square b) triangle c) semi-circle channels 


\section{List of Tables}

Table 1 MAE of correlations 


\section{Tables}

Table 1 Mean Average Error (MAE) of correlations

\begin{tabular}{|ccccccc|}
\hline Shape & Shah [24] & Shah [25] & $\begin{array}{c}\text { Bandhauer and } \\
\text { Garimella [9] }\end{array}$ & $\begin{array}{c}\text { Agarwal et } \\
\text { al. [16] }\end{array}$ & $\begin{array}{c}\text { Akers et al } \\
\text { [1] }\end{array}$ & $\begin{array}{c}\text { Soliman } \\
\text { [27] }\end{array}$ \\
\hline Square & $19.5 \%$ & $18.9 \%$ & $43.9 \%$ & $38.7 \%$ & $166.9 \%$ & $43.7 \%$ \\
\hline Triangle & $29.3 \%$ & $28.6 \%$ & $45.8 \%$ & $42.2 \%$ & $180.8 \%$ & $47.1 \%$ \\
\hline Semi-circle & $22.0 \%$ & $21.4 \%$ & $42.0 \%$ & $37.2 \%$ & $180.1 \%$ & $47.7 \%$ \\
\hline
\end{tabular}

(C) 2011. This manuscript version is made available under the CC-BY-NC-ND 4.0 license http://creativecommons.org/licenses/by-nc-nd/4.0/ 